\title{
More than a Number: Unexpected Benefits of Return on Investment Analysis DeNISE PAN ${ }^{1}$, GabRIELLE WIERSMA ${ }^{2}$, LesLie WILLIAMS ${ }^{3}$, YeM S. Fong ${ }^{4}$
}

\begin{abstract}
In 2010-2011, University of Colorado (CU) librarians implemented a multi-campus pilot study to measure the institutional value of library resources used by faculty in their research. The study incorporated quantitative methods including return on investment (ROI), cost benefit analysis (CBA), and citation analysis of journal articles published by faculty; and qualitative methodologies such as in-person interviews with faculty. The study resulted in a CU ROI model that can be used to measure faculty perceptions of value and the economic benefits of electronic journal collections for faculty research in terms of ROI. The CU ROI methodology provides outcomes beyond a single ROI number and led to unexpected benefits for informing collection development decisions and strategies.
\end{abstract}

\section{INTRODUCTION}

On Monday, September 29, 2008, the US stock market crashed -- losing 1.2 trillion US dollars in a single day (Bajaj \& Grynbaum, 2008). No country or industry was immune to such a dramatic collapse. The Chronicle of Higher Education stated, "higher education responded in an uncharacteristic way: It began to buckle." With no crystal ball, "The crisis will force [campus officials] to make tough choices: Should they reduce payouts to protect their endowments or increase them at a time when students are sure to need more help? And if they have less to invest in people, programs, and buildings, which should come first?" (Wilson, 2008, Squeezing the Middle Class para.11). Universities have endured economic downturns before. However, this financial crisis began to question old assumptions in new ways. In the article entitled "Seeking the New Normal: Budget Strains Force Radical Change," Henderson and Bosch (2010) assert "[e]ven when the economy improves, increased funds for libraries are not likely to be at the top of the list for new spending priorities." In this context, the stage has been set for new interpretations and definitions of library values and contributions to university missions and outcomes.

For collection development and acquisitions librarians at the University of Colorado, the economic downturn along with increased scrutiny of library materials budgets from deans, directors and administrators created an opportunity to investigate ways to demonstrate library value. The University of Colorado System (comprised of three institutions, four campuses, and five libraries) has a tradition of purchasing electronic materials collaboratively. This institutional library consortium focuses on leveraging library budgets to jointly license resources and streamline procurement and legal review. In the fiscal year 2010 (July 2009 to June 2010), the collective buying power was over seven million dollars and shared e-resources ranged from a single journal title to large publisher packages. To determine the return on investment of CU System joint purchases for university administrators, CU librarians conducted a cost benefit analysis of combined budgets and also gathered personal accounts and anecdotes that described the economic benefit that students and faculty received from consortia purchases. The results of this initial study, previously published, "provided compelling evidence for the value of collaborative purchasing to library administrators and university officials. In the end, they were

\footnotetext{
${ }^{1}$ University of Colorado Denver

2 University of Colorado Boulder

${ }^{3}$ University of Colorado Denver

${ }^{4}$ University of Colorado Boulder
} 
able to take their consortia purchases 'off the table' for cuts and continue to provide greater access to eresources for at least another year" (Pan \& Fong, 2010, p. 190).

Although CU librarians successfully conveyed positive cost benefit data to management, the ROI analysis of consortia spending did not provide direct evidence of how library collections support faculty research. The need to answer the question "How is the relationship between library resources and scholarly outcomes measured?" became evident in the fall of 2010 when the University of Colorado Denver's Auraria Library was preparing for their academic department program review, as required by the CU Board of Regents and the Colorado Department of Higher Education. The self-study portion of the review asked the Auraria Library to describe how the relationship between library resources and instructional and scholarly outcomes is measured, and how these results can be used to revise and strengthen programs. Given time limitations, traditional and readily available library data was used for the program review, but these experiences prompted the authors to develop the CU ROI pilot study (Pan, Williams, Wiersma, \& Fong, 2012).

The CU ROI pilot study attempts to measure the impact of library collections on faculty research outcomes by determining if the library was able to provide access to the electronic journals faculty needed for their publications. The investigators adopted a shared research protocol that incorporated both quantitative and qualitative methods, including citation analysis of published journal articles and content analysis of faculty interview questionnaires. In order to measure a return on investment, the authors assigned a monetary value to journal articles used in research, identified library subscription costs, and developed a formula for determining faculty benefits from library collection expenses. In the context of experiences at CU Boulder, Denver, and Anschutz Medical campuses, the authors will provide a literature review of library value studies; describe their procedures for articulating values, developing metrics, and calculating results of the $\mathrm{CU}$ ROI model; and highlight examples of maximizing indirect benefits from the ROI process.

\section{LIBRARY VALUE STUDIES}

Since the early 1990s, libraries have used ROI/CBA to measure the value of their collections and services. Economic pressures have motivated public libraries to conduct valuation studies to demonstrate how taxpayer funding benefits citizens and communities. Imholz and Arns (2007) provide a summary and assessment of 17 public library valuation studies completed from 1998 to 2007 . They argue that "cost/benefit analysis appears to be the most effective language for conveying the efficiency of investments of tax dollars in public libraries to public constituents" (Ibid., 2007, p. 45). Covering a similar time period, 1995-2008, Aabø (2009) offers an international meta-analysis or quantitative evaluation of previous empirical studies. Findings show that $84.2 \%$ (32 out of 38 ) studies focus on public libraries world-wide. With this sample size, Aabø (2009) states, “...a tentative conclusion can be drawn. The results shown in these studies indicate that for each dollar of taxpayers' money invested in public libraries, the libraries - on average - return a value to the citizens of four to five times more" (p. 322).

In addition to justifying budgets, public library impact studies have applied ROI/CBA analysis to other circumstances. Matthews (2011) identifies three additional uses of ROI/CBA analysis: to prioritize alternative and scarce resources; to evaluate an existing project or service; and to support a decision quantitatively. He cautions, however, "[r]elying on a single measure, such as Return on Investment, is not likely to produce a positive reaction among the library's funding decision makers year after year" (Ibid., 2011, p.11). Simply stated, there is "no silver bullet." Rather, libraries may be more continuously successful by establishing an "overall framework for displaying and reporting several key performance 
measures to be effective among decision makers and stakeholders. The library's ROI could be one of the key performance measures" (Ibid.). Both Matthews (2011) and Holt (2007) describe the indirect benefits or values public libraries provide to their patrons. For example, based on thousands of interviews conducted during a CBA study, Holt (2007) identified eight services valued by public library users: time savings; financial savings; convenient location reducing traveling time; access to materials; assistance by library staff; services for children; access to technology; and provide good value for taxes paid.

Responding to similar economic pressures as public libraries, medical libraries have been conducting reports and developing tools to measure impact with ROI and CBA. For example, a work group of Department of Veterans Affairs (VA) hospital libraries recognized the need to develop a standardized method of measuring return on investments. The VA Library Network Librarians' approach includes three components: Return on Investment Analysis tool; a Library Scorecard; and Management Support Report (Jemison et al., 2009). Furthermore, in 2008 and 2011 the Health Sciences and Human Services Library (HS/HSL) of the University of Maryland used an automated tool developed by the National Network of Libraries of Medicine (NN/LM), Mid-Continental Region, to justify their annual book and journal expenditures (Bodycomb \& Del Baglivo, 2012). A majority of these public and medical library analyses focus on quantifying the benefits of library services for patrons.

More recently, academic libraries are responding to the growing need to connect library services and collections with institutional outcomes. Mezick (2007) developed a study to demonstrate how expenditures on library resources and staff services contribute to student persistence and retention. Her research was based on data provided by the Association of Research Libraries (ARL), Association of College and Research Libraries (ACRL), and Integrated Postsecondary Education Data System (IPEDS) of the National Center for Education Statistics (NCES). Mezick (2007) asserts that “... while statistically significant relationships exist between each category of expenditure and student retention within every Carnegie Classification, the strongest relationships exist between total library expenditures, total library materials expenditures, and serial expenditures at baccalaureate colleges" (p. 564). Creaser and Spezi (2012) conducted eight case studies using interviews and surveys in Scandinavia, USA, and the United Kingdom to study the value of academic libraries for teaching and research staff. Their research revealed "more evidence of activity rather than evidence of value and impact, especially value to and impact on teaching and research staff" (p.1).

While public and special libraries were early adopters of ROI, academic libraries have also used ROI to demonstrate value. Tenopir and King (2007) interviewed faculty to determine the quality and value of journal article readings. The study found that having access to electronic journals saved faculty time and increased the number of articles they read over time. As a result, they calculated "ROI in the journal collection made by the university" by estimating how much time and money was saved by having access to the library's e-journal collection (p. 204).

In 2008, the University of Illinois at Urbana-Champaign (UIUC) produced a major study using ROI/CBA to measure the value of library collections, focusing on income generation through grants as opposed to cost savings. According to Luther (2008), the case study was framed with an economic perspective and "using the ROI model with UIUC data produced a return of $\$ 4.38$ in grant income for every dollar invested in the library in 2006" (p.4). Over the next couple of years, the ROI model created in the UIUC case study was replicated in eight institutions and in eight countries (Tenopir, 2010b). Tenopir (2010a) found that the mission and subject emphasis of the institution impacted the ROI of e-journal values. She explains the variation in terms of "the purpose of the institution, with the high being for a pure research institute and lower for teaching/research universities in countries without a high number of competitive 
grant funds...[and] subject discipline, which may account for the differences between institutions depending on the degrees they offer or relative size of subject disciplines" (p. 45). Furthermore, she warns of relying solely on ROI for measuring the value of library collections and services. Similarly, Sidorko (2010) voices his concern with the complexities of individual countries and institutions, data gathering process, and using grant funding as the basis of demonstrating ROI. He articulates the need to "highlight this growing need and to move some way towards developing a methodology, or more likely, methodologies, that can be adapted contextually to suit institutional individuality and idiosyncrasy" ( $p$. 652).

Likewise, publishers have recognized their vested interest in helping libraries identify products and services that provide the most value to the university community and best support university mission and goals. For example, the research and advisory firm Outsell prepared the report "Establishing Value and ROI: Investing in STM E-journals and E-books" at the request of Springer and Loughborough University was commissioned by SAGE to write "Working Together: Evolving Value for Academic Libraries" (Hydock, McShea, \& Ohri, 2009; Creaser \& Spezi, 2012). The Outsell report further explains that, "[a]ssessing and demonstrating the value of paid information is a top issue for libraries and information centers today, with most information managers facing a real struggle to put together all the pieces needed to demonstrate the true worth of information and the return on investment (ROI)...Value is inherently subjective, with different assessments from one individual to another, from one user group to another, and across an organization" (Hydock, McShea, \& Ohri, 2009, p. 5).

Several additional initiatives have emerged to measure the contribution of academic libraries. Some notable examples include: the Lib-Value Project funded by a three-year grant from the Institute of Museum and Library Services awarded to the University of Tennessee, Knoxville, in collaboration with the University of Illinois at Urbana-Champaign Libraries and the Association of Research Libraries (2010); the Library Assessment Conference sponsored by ARL, the University of Virginia Library, and the University of Washington Libraries (2012); and The Value of Academic Libraries: A Comprehensive Research Review and Report developed for the Association of College \& Research Libraries by Oakleaf (2010). Strong participation by institutions and associations demonstrates the importance of identifying and implementing library value studies.

\section{DeVeloping The CU ROI Pilot Study}

Each of the three CU campuses is different in size, mission, graduate programs, student population and resource allocations. Recognizing these differences the researchers sought to develop a consistent methodology for the pilot study that could be applied to each institution regardless of size or mission. The CU ROI model was largely inspired by the research at the University of Illinois at Urbana-Champaign which used the total dollars spent on library collections and services as the costs and the dollars returned in sponsored research awards as the benefits (Luther, 2008, p. 8). The CU ROI model uses the library's journal subscription expenses as the costs and the average price that faculty would have to pay to purchase an article, if the library did not subscribe, as the benefits (Pan, Williams, Wiersma, \& Fong, 2012). The study also builds upon Tenopir's suggestion that "ROI calculations should be expanded beyond grant income to include the value of all key library products and services that support the mission of the institution" (Tenopir, 2010b, p. 3).

The pilot study consists of four overarching phases: 1) defining value, 2) gathering data, 3) calculating $\mathrm{ROI}$, and 4) analyzing results. In addition to quantifying a value that can be tied to scholarly outcomes, each phase of the process can provide opportunities to discover insights such as improving or 
establishing a relationship with a department and individual faculty members; promoting library services; and identifying highly valued journals, patterns of faculty use, and alternative serials purchasing options.

\section{Phase 1: Defining value}

Many methods exist for defining and measuring library value. According to Oakleaf (ACRL 2010), libraries most often define value through "use" or utility, and financial value. "Use" focuses on counting inputs and outputs like circulation statistics, full-text downloads, or citations. Counting usage measures "implicit value" by equating use with value and concludes that libraries are valued because they are used (Tenopir 2007, 2011). While informative, usage statistics "do not show why someone used or requested a source or the outcomes on their work from using that source" (Tenopir, 2009, p.10). However, they can be paired with explicit values which seek to capture why the library collections are important to users. Explicit values can be provided by observing or interviewing users about their use of library collections and identifying what they produced or achieved as a result (ACRL 2010, Tenopir 2011). Combined with implicit values, "qualitative methods can add to [the] story of the value and outcomes of library collections and services" (Tenopir, 2011, p. 9). Finally, financial value is often based on a formula of dividing perceived benefits by perceived costs to determine library value. Costs and benefits may be defined as prices, time, effort provided by library or possible exchange value received by patrons from a library service or resource. Financial value can be presented as a cost benefit analysis or expressed as return on investment.

The CU ROI methodology combines multiple definitions of value to measure the impact of library collections on faculty research. The authors initially selected return on investment and cost benefit analysis as financial value metrics that would appeal to academic administrators. However, as Tenopir (2011) explains, ROI is a "derived value" that requires "multiple types of data collected on both the returns (benefits) and the library and user costs (investment) to explain value in monetary terms"(p.6). The CU ROI pilot study measured use of library collections by counting journal citations in faculty articles. Unlike generic usage statistics which are disconnected from scholarly outcomes, counting cited reference signify use of a source that resulted in a published article. In addition, faculty authors were interviewed to determine how they acquired scholarly information for their research. Faculty at each campus indicated that the majority of the resources they used in their research were obtained from library sources. The authors positioned financial value in terms of the library's costs to subscribe to journals cited compared to the pay-per-view costs for the same cited articles. As outlined in the following phases, the study led to the development of a ROI model that incorporated faculty perceptions of value and the economic benefits of electronic journal subscriptions for supporting faculty research.

\section{Phase 2: Gathering Data}

The next phase of the study required identifying, recruiting, and interviewing faculty. The goal of the interviews was to gather curriculum vitae and information on the project participants' use of library materials. While the investigators considered using participants from the same discipline on all three campuses, time constraints made that approach difficult to achieve. Instead, each campus followed similar protocols and identified potential participants as academic faculty with research responsibilities. Faculty members with appointments that focused on teaching without a research requirement were removed from the participant pool. Researchers from all three campuses consulted with subject liaisons to identify academic departments or individual faculty members who would be willing to join the study. Both the Denver and Anschutz Medical campuses concentrated on a single academic department, the 
Chemistry and Physical Therapy departments respectively. In contrast, the Boulder study recruited participants from a variety of departments, such as Engineering, Business, History, Philosophy, Sociology, Economics and Asian Studies.

At the Denver campus, Pan conferred with the Science Collection Development Librarian, and also met with the Dean of the College of Liberal Arts and Sciences and the Chemistry department chair to explain the project in person. Pan mentioned their endorsement and carbon copied the department chair on an email invitation to each full-time faculty member in the department which persuaded nearly $70 \%$ ( 9 out of 13) to participate (Pan, Wiersma, \& Yem Fong, 2011). Similarly, at the Anschutz Medical Campus, Williams and an academic liaison obtained support from the Physical Therapy program director, and recruited 57\% (12 out of 21) of the department (Williams, Pan, Wiersma, \& Fong, 2012). At the larger research-focused Boulder campus, Fong and Wiersma enlisted the support of the Boulder Faculty Library Committee, a faculty committee of representatives from across campus units, and the Dean of Libraries, who sent an email to all faculty members inviting their participation. Fong and Wiersma also asked subject liaisons to actively recruit participants through their departmental faculty contacts and invited liaisons to sit in on the interviews (Wiersma, Pan, Williams, \& Fong, 2012). Even though the researchers were not able to interview a representative sample of the faculty on each campus, the pilot study explored several methods to approach and recruit faculty that could be used to complete a more comprehensive study in the future.

During the interviews, the researchers described the goals of the project; requested a copy of each participants's curriculum vita and syllabi for the citation analysis; and asked 4 questions about their use of library resources.

1. In your most recently published article, for every article you cited how many additional articles did you read but did not cite?

2. Approximately what percent of the articles cited or read were obtained from the following:

- electronically from the library?

- in print format from the library?

- via Interlibrary loan from the library?

- from non-library sources?

Faculty were asked to describe their most recently published article and describe how many of the resources cited in that publication came from library or other sources. However, these encounters also presented an opportunity for the librarians to gain feedback on existing collections and services. Similar to Holt's (2007) study, faculty participants at each campus identified resources and services of value to their research and teaching.

For example, the Boulder faculty who participated in the pilot study reported differences in the use of electronic journals and differences in collection needs based on discipline. For faculty in the humanities, although access to journal literature was important, they were more interested in discussing access to primary sources, monographs and reference literature. Social science and science faculty were much more concerned about maintaining access to key online journals and databases in their fields. Boulder faculty uniformly praised the University Libraries' interlibrary loan services and noted that the transition to e-books was useful for teaching. The interviews also generated discussions about interdisciplinary needs and the complexities of a recent journal cancellation project. Since several subject specialists sat in on the interviews, these conversations created greater relationship building opportunities with their faculty. In addition to answering questions about how to access library collections, the librarians were able to promote a new document delivery service and offer instruction sessions for students. 
While Boulder researchers were collection development librarians who typically have on-going interactions with faculty, the interviews offered a new opportunity for acquisitions and technical services librarians from the Denver campus and Health Sciences Library to liaise directly with patrons. For instance, during interviews at the Anschutz Medical Campus faculty members expressed an unremitting need to be knowledgeable about the most recent developments in their field, focusing predominantly on research published in journals during the last year. The critical requirement for immediate notification of the latest publications was revealed when one faculty member shared that he subscribes to table of contents alerts for more than 25 journals. Study participants consistently articulated their appreciation for the focus on current and online journal content available through the Health Sciences Library. They valued anytime and anyplace access to the most essential research titles, such as the Journal of Orthopedic \& Sports Physical Therapy, for their research and teaching.

While expressing their preference for immediate access to the most current journal holdings, the Physical Therapy faculty members conveyed their understanding of budget limitations. They did not expect the Health Sciences Library's collection to include backfile access or subject areas outside of medical and allied health. Study participants said that they were satisfied with relying on interlibrary loan (ILL) for older articles and periphery topics, despite the Health Sciences Library being the only library within the CU System that operates ILL as a cost-recovery unit by charging faculty for services.

Similarly, the Denver Chemistry faculty expressed high praise for Auraria Library's collections and services. When asked for suggestions to improve the collection, they consistently commented on their satisfaction with the library's subscriptions to core titles in their field. However, a few months after the ROI interview, one study participant emailed Pan with a request for greater access to American Geophysical Union (AGU) journals. Coincidentally, the library had just received the renewal and an offer from the publisher to upgrade from a few titles to the complete complement of AGU titles. Knowing the faculty member's need for these journals was a contributing factor for the Denver campus to make a decision to contribute to a CU system consortia purchase of the AGU full electronic journal package.

At the Health Sciences Library, Williams received requests for consultation services on copyright when study participants asked questions such as "can I distribute a copy of an article from my personal journal subscription to students?" and "if I give the library a reading list, can I get those texts put on reserve?" Both Williams and Pan had a chance to deliver one-on-one instruction on how to use the library website and clarify the library's buyer role in providing access to propriety publisher content. On the Boulder campus, Fong and Wiersma answered queries about access to specific resources and the liaisons, who attended interviews, were able to learn more about the research projects of the faculty participants. Several faculty members conveyed a vague notion that the library provided access to journals oncampus. They welcomed further explanation on how to achieve off-campus access to library databases and journals via Google Scholar. In addition, the interview process also inspired new research collaboration at the Denver campus. Although a Chemistry teaching instructor did not publish and therefore could not participate in the CU ROI study on faculty outcomes, she was very interested in the project. Eventually she and an Instruction Librarian collaborated with Pan to develop a separate case study to quantify the benefits Chemistry students receive in their education by using library collections.

In hindsight, the initial phase of the CU ROI model was very challenging. Identifying, recruiting, scheduling, and interviewing study participants created logistical obstacles and was more time consuming than anticipated. Despite these efforts, the qualitative method provided valuable insights and richer context for understanding faculty needs. The researchers successfully gathered details on 
study participants' publications and use of library materials. By re-conceptualizing the interviews as an outreach opportunity, however, a ROI study can generate unexpected learning and teaching moments that establish or improve communication and relationships with a department and individual faculty members.

\section{Phase 3: Calculating ROI}

Using data gathered from faculty interviews and curriculum vitae, the authors derived the ROI value of library collections used to support faculty research, i.e. scholarly articles written by pilot participants. As a result, the CU ROI model shows the percentage increase in value on dollars spent by the library (in terms of journal subscriptions) to achieve a benefit for faculty (derived from potential savings from the average cost they would have had to pay to buy articles directly from publishers). Furthermore, the CU $\mathrm{ROI}$ model, using cost benefit analysis, identifies the return benefit academic faculty received for every dollar the library spent on journal subscriptions.

The CU ROI model is based on cost benefit analysis (CBA) and return on investment (ROI). CBA is the ratio showing dollar value of benefits gained for dollar value of costs as represented by the following formula:

\section{Benefits $\div$ Costs $=$ CBA}

ROI uses the same values as $\mathrm{CBA}$, however, $\mathrm{ROI}$ is shown as a percentage. It conveys the return or increase in value on dollars spent to achieve a benefit. The formula is:

$$
\text { ((Benefits }- \text { Costs }) \div \text { Costs }) \times 100=\text { ROI }
$$

To calculate the benefits and costs, the CU ROI model (see Table 1) applies a combination of data obtained from faculty interviews, citation analysis, and costs. Library costs are the library's expenditures to purchase online journal subscriptions for the references cited in faculty publications. Faculty benefits are defined as the average price that faculty would have had to pay in order to buy their cited articles directly from publishers (Pan, Williams, Wiersma, \& Fong, 2012).

Table 1: The CU ROI model

\begin{tabular}{|lll|}
\hline \multicolumn{2}{|c|}{ Variable } & Data Source \\
\hline A & \# of published articles in 1 year & CV \\
\hline B & \# of all cited references & $\begin{array}{l}\text { Citation } \\
\text { Analysis }\end{array}$ \\
\hline C & \# (\%) of cited references from journals & $\begin{array}{l}\text { Citation } \\
\text { Analysis }\end{array}$ \\
\hline D & \# (\%) of cited references from online subscriptions & $\begin{array}{l}\text { Citation } \\
\text { Analysis }\end{array}$ \\
\hline E & \# of additional articles read (but not cited) & Interview Q1 \\
\hline F & $\begin{array}{l}\text { \# of additional articles read from journals (but not } \\
\text { cited) }\end{array}$ & E x C\% \\
\hline
\end{tabular}




\begin{tabular}{|lll|}
\hline $\mathrm{G}$ & $\begin{array}{l}\text { \# of additional articles read from online journals } \\
\text { (but not cited) }\end{array}$ & $\mathrm{F} \times \mathrm{D} \%$ \\
\hline $\mathrm{H}$ & $\begin{array}{l}\text { \# of citations and articles read (but not cited) from } \\
\text { online resources }\end{array}$ & $\mathrm{D}+\mathrm{G}$ \\
\hline $\mathrm{I}$ & $\begin{array}{l}\text { Average cost per article (random sampling of } \\
\text { publisher pay-per-view prices) }\end{array}$ & $\$ \$ \$$ \\
\hline $\mathrm{J}$ & $\begin{array}{l}\text { Faculty benefit - average cost to buy articles } \\
\text { directly from publisher with pay-per-view }\end{array}$ & $\mathrm{HXI}$ \\
\hline $\mathrm{K}$ & $\begin{array}{l}\text { Library costs - online journal subscriptions for } \\
\text { cited references }\end{array}$ & \$\$\$ \\
\hline $\mathrm{ROI}$ & $\begin{array}{l}\text { Percentage showing return or increase in } \\
\text { value on dollars spent (by library) to achieve a } \\
\text { return (for faculty) }\end{array}$ & $\mathrm{J}-\mathrm{K} / \mathrm{K} \times 100$ \\
\hline CBA & $\begin{array}{l}\text { Ratio showing dollar value of benefit gained } \\
\text { (by faculty) for dollar value of costs (for library) }\end{array}$ & $\mathrm{J} / \mathrm{K}$ \\
\hline
\end{tabular}

Faculty responses to interview questions were collected and applied to the appropriate variables. For example, from the first interview question ("In your most recently published article, for every article you cited how many additional articles did you read but did not cite?") the number of additional articles read but not cited were determined (variable E).

Study participants' most recent research publications were identified from the curriculum vitae. The authors limited the scope to articles published within two years of the study which made the citation analysis more manageable for the pilot study. After obtaining copies of the faculty's articles, the source of full-text access for each journal article cited was identified. Based on the cited references in each article, three variables were calculated: the number of all cited references (variable B); the percentage of journal citations (variable C); and the percentage of journal citations from online library resources (variable D).

After the interviews and citation analysis were finished, the authors calculated library costs. The library costs were based on the prices of subscriptions paid by each library for journals cited by the study participants (variable K).

The final variable needed to measure ROI/CBA is the faculty benefit or a monetary value for the cost of having access to library collections (variable J). Poll and Payne (2006) explain "as most library services have no equivalent on the common market and therefore no 'market prices' can be determined, two other ways have been tried for assessing an economic value: assessing time costs (replacement value of a client's time) and using the contingent valuation method" (p.554).

In most cases, contingent valuation constructs a market by surveying current and potential library users to determine their willingness-to-pay (WTP) and willingness-to-accept (WTA). Poll and Payne (2006) describe WTP as "what would you pay for maintaining this library/this special library service" and WTA as "which sum would you accept as an equivalent if this library/this special service were given up" (p. 554). For example, Tenopir and King (2007) used contingent valuation to estimate the implied value of journal collections. Faculty survey participants were asked "to indicate what they would do if the source they used for their last reading (e.g. library collection) was not available to them. Then [they asked] 
them to speculate what it would cost in terms of money or time to get the same information if the source they used was not available to them" (Tenopir and King, 2007, p.204).

Faculty members have many options for obtaining materials they need for their research. These alternatives could be free or have a cost. For example, they could be borrowing materials from a colleague (free), obtaining a copy from the library or Interlibrary loan services (free at the Boulder and Denver campuses but a fee-based service at the Anschutz Medical Campus), or paying for an article directly from a publisher. Instead of relying on a subjective value for faculty WTP, the CU ROI model adapted the contingent valuation method to simulate a market value for library collections.

The CU pilot study used a random sample of journal titles cited in faculty publications to arrive at an average price per article that a faculty member would have to pay in order to obtain an article directly from the publisher. For example, at the Denver campus, study participants cited 158 journals. Pan randomly selected 15 journals (10\% of 158) that were available from the publishers' pay-per-view services. Using the pay-per-view article price for each of these 15 journals, Pan calculated the average cost per article for her random sample to be $\$ 34.22$ (variable I). This amount was multiplied by the number of citations and articles read, but not cited, from online resources (variable $\mathrm{H}$ ) to calculate the faculty benefit (variable J).

\section{Phase 4: Analyzing Results}

After gathering and applying data to the $\mathrm{CU}$ ROI model, the authors were able to calculate ROI results for each campus. For every dollar invested in journal subscriptions, using the average pay-per-view article price, the CU ROI model produced a positive return of $66 \%$ and $144 \%$ for Denver and Boulder respectively, and a negative return of $-19 \%$ at the Anschutz Medical Campus (see Table 2).The researchers calculated low and high pay-per-view article prices based on standard deviation from the average pay-per-view article price. With standard deviation, the authors are $95 \%$ confident the average price falls somewhere within this range. For example, for CU Denver, a low pay-per-view price of $\$ 31.94$ results in a $55 \%$ ROI while a high pay-per-view price of $\$ 36.51$ results in a $77 \%$ ROI. In other words, CU Denver still had a positive ROI regardless of the low and high article prices. The outcomes from CU Boulder, Denver, and Anschutz Medical campuses are summarized in Table 2 (Pan, Williams, Wiersma, \& Fong, 2012, p. 15).

While these ROI figures were informative, they were not generalizable for each institution given the small number of faculty who participated in the study. These inconclusive findings could have caused the researchers to feel unsatisfied. By conducting interviews with, examining references cited by faculty, and researching costs for journal subscriptions and articles, however, they were able to discover new and surprising perspectives on faculty needs. 
Table 2: Pilot Results for the University of Colorado

\begin{tabular}{|r|c|c|c|}
\multicolumn{2}{|c|}{$\begin{array}{c}\text { Average } \\
\text { Article Cost }\end{array}$} & $\begin{array}{c}\text { Low Standard } \\
\text { Deviation }\end{array}$ & $\begin{array}{c}\text { High Standard } \\
\text { Deviation }\end{array}$ \\
\hline CU Boulder & & & $\$ 29.66$ \\
\hline cost per article & $\$ 32.53$ & $\$ 2.05$ & $\$ 35.41$ \\
\hline ROA & $\$ 2.44$ & $105 \%$ & $\$ 2.44$ \\
\hline CU Denver & $144 \%$ & & $144 \%$ \\
\hline cost per article & $\$ 34.22$ & $\$ 31.94$ & $\$ 36.51$ \\
\hline CBA & $\$ 1.66$ & $\$ 1.55$ & $\$ 1.77$ \\
\hline ROI & $66 \%$ & $55 \%$ & $77 \%$ \\
\hline CU Anschutz Medical Campus & & & $\$ 42.27$ \\
\hline cost per article & $\$ 36.36$ & $\$ 30.44$ & $\$ 0.95$ \\
\hline CBA & $\$ 0.81$ & $\$ 0.68$ & $-5 \%$ \\
\hline ROI & $-19 \%$ & $-32 \%$ & \\
\hline
\end{tabular}

There are many factors that could shift ROI from positive to negative including library journal subscription costs, faculty productivity, and the cost per article from publishers' websites. Initially, one may conclude that the resulting ROI value could be used to signify whether or not the library's collection development strategy is supporting a department. For example, the Denver campus had a positive ROI which could indicate that the library is providing access to the majority of the resources needed to support faculty research for the Chemistry department. In contrast, the Anschutz Medical Campus had a negative ROI for the Physical Therapy department, which could suggest that the library has gaps in the collection or is subscribing to resources that are not getting optimal use by faculty. However, because results varied significantly from between campuses and year to year, the authors realized that ROI is still just one metric that needs to be placed within the overall context of the data collected and used in conjunction with other collection assessment metrics. Pan, Wiersma and Fong (2011) recognize that "like any statistical measure, ROI and CBA calculations are only meaningful when put into context" ( $p$. 460).

The results of the CU ROI pilot study provide further evidence that multiple measures are needed to demonstrate library value. "The benefit of multiple methods is that numbers in and of themselves rarely tell the full story. Interviews and surveys allow the faculty to tell their story of how they use the library in their grant proposal process, in teaching, and in their research and work life" (Tenopir, 2010a, p. 46). In addition to the ROI calculation, the mixed methodology approach of the CU ROI model provides data that could be used to inform collection development decisions and strategies.

For example, pairing citation analysis data with feedback from faculty interviews could be used to inform decisions regarding renewals and cancellations. Libraries often seek input from campus colleagues before cancelling journal subscriptions or moving materials offsite. Faculty members typically provide input about core journals that represent the research interests of the entire department. However, it can be difficult to identify niche publications that are important to specialized research within the discipline. During the interviews at the Boulder campus, study participants often mentioned relevant journals in their field as well as resources that were important to their particular research. Citation analysis confirmed the importance of many core journals within each field and also identified journals that were necessary for individual faculty research. Both qualitative and quantitative 
methods provided valuable feedback about journals that would likely be candidates for cancellation based solely on cost, usage, or subject coverage.

By the same token, the model could provide an alternative metric for cost per use calculations and usage statistics. Cost per use calculations and usage statistics indicate that the library's existing collection is being accessed. They cannot identify, however, the significance of that use. By combining citation analysis and usage data, detailed analysis at the Denver campus revealed that some low use journals actually resulted in a high number of faculty citations. One of the low usage journals (18 fulltext articles accessed) was cited at a greater rate than the highest ranked journal and most accessed journal within the field. This title might have been a candidate for cancellation based on usage alone, but the added citation rate information provided additional context for measuring the value of this journal (Pan, Wiersma, \& Fong, 2011).

The CU ROI model could provide a framework for evaluating overall collection development strategies and provide evidence to support the investigation of alternative acquisition models. As a result of the negative findings, the Health Sciences Library began to analyze their collection development policy and explore options to improve the collection and services. Since 2005, the Health Sciences Library has been increasingly transitioning from print to electronic resources in response to a campus LibQual survey. Today $98.5 \%$ of the materials budget is dedicated to continuing online materials with annual subscription fees. After several years with no or minimal increases, the materials budget is failing to keep pace with inflation despite the use of common strategies for controlling costs such as negotiating multi-year deals with annual price caps and participating in consortial purchases (Williams, Pan, Wiersma, \& Fong, 2012).

From a detailed analysis of the journals that were cited by faculty, Health Sciences librarians discovered that the library was providing access to the core journals for the discipline but the cost of those journals was relatively high compared to resources in other disciplines. To make matters worse, in 2012 serials prices increased six percent versus five percent in 2011 while "the Consumer Price Index advanced 2.9 percent for 2011, which means serials inflation continues to far exceed general inflationary pressures... Prices for science, technology, and medical (STM) serials remain the highest, compared with prices for serials in other subject areas..." (Bosch \& Henderson, 2012, On the upswing: serials prices para. 4).

In the "new normal" economic realities, the Health Sciences Library's negative CU ROI results foreshadow the future for many academic libraries - flat or decreased budget in stark conflict with high renewals - and reinforce concerns regarding the sustainability of the existing models for purchasing electronic content. At the Health Sciences Library, the collection development conversation changed from undertaking a typical journal cancellation process to meet budgetary goals to considering alternative acquisitions and access models. Should a library forgo the greater access provided by big deals in favor of smaller deals that provide subject specific collections? Should the library negotiate lower prices in exchange for current access and for relinquishing perpetual and archival rights? Should the library explore pay-per-view models and patron-driven acquisitions? At the present moment, the ROI results inspire more questions and definitive answers remain to be determined.

\section{CONCLUSION}

The CU ROI pilot study developed and tested a theoretical model for measuring the impact or value of library resources in faculty research. While each campus applied the same protocols, the findings of the study provided institutional insights that were meaningful to each institution's mission. With this in 
mind, the researchers discourage definitive assertions or interpretations of their pilot study results. Although the final ROI figures were informative, they are not generalizable for each institution given the small number of faculty who participated in the study. However, if applied appropriately, the CU ROI model has the potential for demonstrating how library collections support research outcomes or, alternatively, results can support a transition to new acquisition and access strategies.

The process of collecting and examining data to calculate a ROI value provided unexpected benefits including relationship building with academic departments, increased awareness of resource needs, promotion of library collections and services, and evidence to support the investigation of alternative acquisition models. In the final analysis, the study was valuable for more than the number that was derived as ROI. Although the study required a great investment of time and careful deliberation and analysis, the process of collaborating with colleagues at other campuses and engaging faculty in the research was rewarding. The interviews were an excellent outreach opportunity. These one-on-one conversations provided an opportunity for in-depth discussions about collections relevant to faculty research and elicited information about faculty member's preferences for formats, interlibrary loan, and access to resources via the libraries' catalogs. Moreover, the added benefits of outreach and learning about faculty research are incentives that the authors feel outweigh the challenges of implementing a ROI study.

\section{REFERENCES}

Aabø, S. (2009). Libraries and Return on Investment (ROI): A Meta-Analysis. New Library World, 110(7/8), 311-324.

Association of College and Research Libraries (ACRL). (2010, September). Value of Academic Libraries: A Comprehensive Research Review and Report. Researched by Megan Oakleaf. Chicago: Author. Retrieved from www.acrl.ala.org/value

Bajaj, V., \& Grynbaum, M. M. (2008, September 29). For Stocks, Worst Single-Day Drop in Two Decades. New York Times. Retrieved from http://www.nytimes.com

Bodycomb, A. \& Del Baglivo, M. D. (2012). Using an Automated Tool to Calculate Return on Investment and Cost Benefit Figures for Resources: the Health Sciences and Human Services Library Experience. Journal of the Medical Library Association, 100(2), 127-131.

Bosch, S. \& Henderson, K. (2012). Coping with the Terrible Twins: Periodicals Price Survey 2012. Library Journal, 137(8), 28-32.

Creaser, C. \& Spezi, V. (2012, June). Working Together: Evolving Value for Academic Libraries. Report commissioned by SAGE. Retrieved from http://libraryvalue.files.wordpress.com/2012/06/ndm5709-lisu-final-report_web.pdf

Henderson, K. S. \& Bosch, S. (2010). Seeking the New Normal: Budget Strains Force Radical Change. Library Journal, 135(7), 36-40.

Holt, G. (2007). Communicating the Value of Your Libraries. The Bottom Line: Managing Library Finances, 20(3), 119-124.

Hydock, J., McShea, J. \& Ohri, M. (2009, December 16). Establishing Value and ROI: Investing in STM Ejournals and E-books. Report commissioned by Springer. Burlingame, CA: Outsell. Retrieved from http://www.springer.com/librarians/for+r+\%26+d?SGWID=1-40475-12-700104-0

Imholz, S. \& Arns, J. W. (2007). Worth Their Weight: An Assessment of the Evolving Field of Library Valuation. Public Library Quarterly, 26(3), 31-48.

Jemison, K. et al, (2009). Measuring Return on Investment in VA Libraries. Journal of Hospital Librarianship, 9(4), 379-390. 
Library Assessment Conference. (2012). Building Effective, Sustainable, Practical Assessment. Retrieved from http://libraryassessment.org

LIB-Value Project. (2010). Value, Outcomes, and Return on Investment of Academic Libraries. Retrieved from http://libvalue.cci.utk.edu

Luther, J. (2008). University Investment in the Library: What's the Return? A Case Study at the University of Illinois at Urbana-Champaign. Library Connect White Paper \#1. San Diego, CA: Elsevier. Retrieved from http://libraryconnect.elsevier.com/university-investment-library-what\%E2\%80\%99s-returncase-study-university-illinois-urbana\%E2\%80\%93champaign

Matthews, J.R. (2011). What's the Return on ROI? The Benefits and Challenges of calculating Your Library's Return on Investment. Library Leadership \& Management, 25(1), 1-14.

Mezick, E. M. (2007). Return on Investment: Libraries and Student Retention. The Journal of Academic Librarianship, 33(5), 561-566.

Pan, D. \& Fong, Y. (2010). Return on Investment for Collaborative Collection Development: A CostBenefit Evaluation of Consortia Purchasing. Collaborative Librarianship, 2(4), 183-192.

Pan, D., Wiersma, G., \& Fong, Y. (2011, March 30-April 2). Towards Demonstrating Value: Measuring the Contribution of Library Collections to University Research \& Teaching Goals. Annual Convention of the Association of College \& Research Libraries. Philadelphia, PA. Retrieved from http://www.ala.org/acrl/sites/ala.org.acrl/files/content/conferences/confsandpreconfs/ national/2011/papers/towards_demonstratin.pdf

Pan, D., Williams, L., Wiersma, G. \& Fong, Y. (2012, May 19-21). Beyond ROI: Transitioning Assessment Into Action. Annual Convention of the Acquisitions Institute at Timberline Lodge. Timberline Lodge, OR.

Poll, R. \& Payne, R. (2006). Impact Measures for Libraries and Information Services. Library Hi Tech, 24(4), 547-562.

Sidorko, P. E. (2010). Demonstrating ROI in the Library: the Holy Grail Search Continues. Library Management, 31(8/9), 645-653.

Tenopir, C. (2009, October 5). Measuring the Value and Return on Investment of Academic Libraries. International Conference on Academic Libraries. Delhi, India. Retrieved from http://crl.du.ac.in/ical09/papers/index_files/ical-2_158_377_1_RV.pdf

Tenopir, C. (2010a). Measuring the Value of the Academic Library: Return on Investments and Other Value Measures. The Serials Librarian, 58, 39-48.

Tenopir, C. (2010b). University Investments in the Library, Phase II: An International Study of the Library's Value to the Grants Process. Library Connect White Paper. San Diego: Elsevier. Retrieved from http://libraryconnect.elsevier.com/university-investment-library-phase-ii-international-studylibrarys-value-grants-process-2010

Tenopir, C. (2011). Beyond Usage: Measuring Library Outcomes and Value. Library Management, 33(1), 5-13.

Tenopir, C. \& King, D. (2007). Perceptions of value and value beyond perceptions: measuring the quality and value of journal article readings. Serials, 20(3), 199-207.

Wiersma, G., Pan, D., Williams, L. \& Fong, Y. (2012, April 2-4). Calculating Value: The Nuts and Bolts of Implementing the University of Colorado ROI Study. Electronic Resources \& Libraries. Austin, TX.

Williams, L., Pan, D., Wiersma, G. \& Fong, Y. (2012, May 18-23). Keeping Score: Assessing the Value of Electronic Resources in Faculty Research. Annual Convention of the Medical Library Association. Seattle, WA.

Wilson,W. (2008, October 10). As Credit Crisis Chills Campuses, Worries Mount. The Chronicle of Higher Education. Retrieved from http://chronicle.com 


\section{Suggested Citation (APA):}

Pan, D., Wiersma, G., Williams, L., \& Fong, Y. S. (2013). More than a number: Unexpected benefits of return on investment analysis. Journal of Academic Librarianship, 39(6), 566-572. 